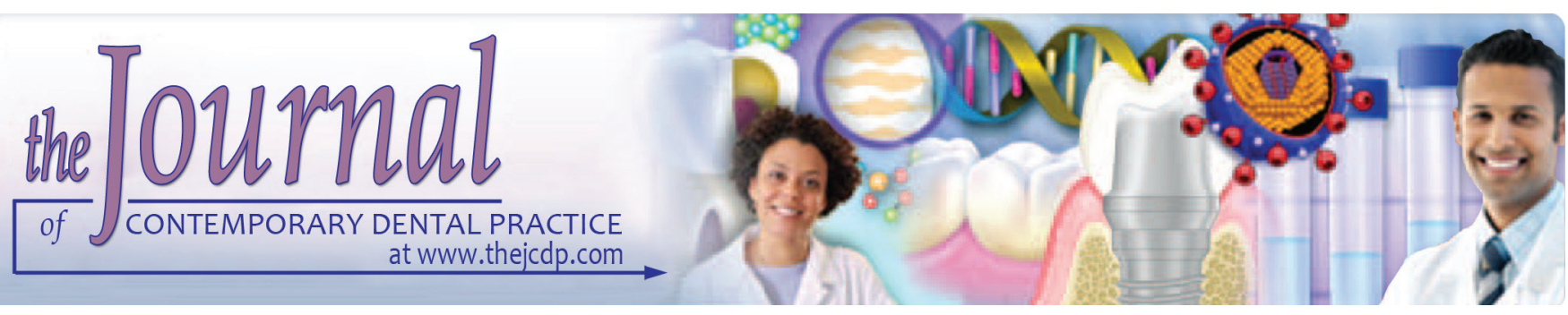

\title{
Periodic Assessment of Peri-implant Tissue Changes: Imperative for Implant Success
}

\author{
${ }^{1}$ Shaifulizan Ab Rahman, ${ }^{1}$ Hazelina Muhammad, ${ }^{2}$ Sanjida Haque, ${ }^{3}$ Mohammad K Alam
}

\begin{abstract}
Aim: The aim of this study was to evaluate the changes in the peri-implant hard and soft tissues and implant stability and to assess the correlation of bone loss and peri-implant probing depth with implant stability.
\end{abstract}

Materials and methods: Twenty-one patients with implants were included in this study and implants were assessed by resonance frequency analysis (RFA). Bone levels of the implants were assessed by measuring mesial and distal bone levels from the periapical radiograph, and soft tissue was assessed from probing depth using a periodontal probe. Implants were assessed for stability and probing depth at pre-loading, at 3 months and 6 months post-loading. RFA and probing depth were statistically compared from different time points. Correlation of probing depth and marginal bone loss with implant stability was also determined.

Results: The average change in implant stability quotient (ISQ) measurements from pre-loading to 6 months post-loading was found to be statistically significant $(p<0.005)$. The average probing depth reduced from $1.767 \mathrm{~mm}$ at pre-loading to 1.671 $\mathrm{mm}$ at post-loading 3 months, and $1.600 \mathrm{~mm}$ at post-loading 6 months. At 6 months of function, radiographic examination yielded $0.786 \mathrm{~mm}$ mesial bone loss and $0.8 \mathrm{~mm}$ distal bone loss. It was found to be statistically significant $(p<0.005)$ but within an acceptable range. No significant correlation was found between implant stability and bone loss; and implant stability and probing depth.

${ }^{1}$ Department of Oral Surgery and Maxillofacial Surgery, School of Dental Science, Universiti Sains Malaysia. Kubang Kerian, Kota Bharu, Kelantan, Malaysia

${ }^{2}$ Department of Orthodontic Unit, School of Dental Sciences, Universiti Sains Malaysia, Kubang Kerian, Kelantan, Malaysia

${ }^{3}$ Department of Orthodontic, College of Dentistry, Jouf University, Sakaka, Kingdom of Saudi Arabia

Corresponding Author: Shaifulizan Ab Rahman, Department of Oral Surgery and Maxillofacial Surgery, School of Dental Science, Universiti Sains Malaysia. Kubang Kerian, Kota Bharu, Kelantan, Malaysia, Phone: +609-7675821, e-mail: shaiful@usm.my
Conclusion: The study revealed an increasing trend in implant stability values with the time that indicates successful osseointegration. Increasing mean values for mesial and distal bone loss were also found.

Clinical significance: The success of dental implants is highly dependent on the quality of bone and implant-bone interface, i.e., osseointegration. The most important factors that influence the survival rate of an implant is initial stability. The present study found the changes in the peri-implant hard and soft tissues and implant stability. This article, while being a prospective study, may show the evidence of successful osseointegration by increasing trend in implant stability (RFA) values with time which can help to the clinician in the long-term management of implants.

Keywords: Implant stability, Osseointegration, Peri-implant, Resonance frequency analysis.

How to cite this article: Rahman SA, Muhammad $\mathrm{H}$, Haque S, Alam MK. Periodic Assessment of Peri-implant Tissue Changes: Imperative for Implant Success. J Contemp Dent Pract 2019;20(2):173-178.

Source of support: Nil

Conflict of interest: None

\section{INTRODUCTION}

Implant treatment is a viable option for replacing missing teeth in current practice. Titanium dental implants are biocompatible devices placed surgically into the mandibular or maxillary bones to support a prosthesis.

The healing process after dental implant placement results in osseointegration, which is the formation of a direct interface between an implant and bone without intervening soft tissue. Osseointegration was discovered and described by P-I Brånemark. ${ }^{1}$ Clinically, there is the existence of an anchorage mechanism, where non-vital components are reliably incorporated into bone and able to persist under normal loading conditions. ${ }^{2}$

The success of dental implants is highly dependent on the quality of bone and implant-bone interface, i.e., osseointegration. ${ }^{3}$ The initial stability is one of the most important factors influencing the survival rate of 
an implant after it is inserted into the alveolar bone. ${ }^{4-6}$ More bone in-growth into the implant surface occurs when there is higher implant stability hence resulting in a higher success rate because of better osseointegration. Factors affecting the initial stability of an implant includes the surgical technique used, the geometry and surface treatment of the implant, and the quality and quantity of the host bone. ${ }^{5}$ Various methods are available to assess implant stability. Histological examination is perhaps the most traditional method. $3,7,8$ This is however invasive. Presently, there are several non-invasive techniques available to measure implant stability. The resonance frequency analysis (RFA) ${ }^{3-9}$ and Periotest ${ }^{3}$ are two such typical methods.

Resonance frequency analysis is explained based on the mechanical principle that as the bone anchorage increases due to positive bone remodeling, the resonance frequency of the implant increases as a result of the increase in the stiffness of the implant-bone interface. ${ }^{3,10}$

Peri-implant soft tissue stability is one of the key factors in timing selection for the placement of final restoration. ${ }^{11}$ Approximately $1 \mathrm{~mm}$ of the gingival recession has been reported within the first 3 months, in a study that evaluated the remodeling of soft tissue from abutment connection surgery to1 year follow-up. ${ }^{12}$ Peri-implant tissue differs from periodontal tissues due to the lack of cementum and periodontal ligament, connective tissue which contains fewer blood vessels and fibroblasts and an attached supracrestal connective tissue which is absent in the latter. ${ }^{11,13,14}$ To obtain esthetic success in implant dentistry, placing the implant with the correct diameter, at the ideal position in relation to the bone, soft tissue, and adjacent tissue is required. ${ }^{12}$ Grunder et al. ${ }^{15}$ focused on the biological limits of the soft tissues around implants in achieving good esthetics. Aso-called "3D Bone to implant" relationship for an ideal soft tissue morphology, was described by these authors, whereby the thickness of connective tissue overlying bone around implants ranged between 2.8 and $3.8 \mathrm{~mm},{ }^{11,16}$ and its height ranged between 3.5 and $5 \mathrm{~mm} .^{17}$ It was hypothesized by these authors that the soft tissue coronal levels after healing were influenced by the original volume of bone and possible bone resorption which occurs both vertically and horizontally for at least $1 \mathrm{~mm}$ following implant installation. Rouck reported by means of radiography, a mean bone loss of $0.98 \mathrm{~mm}$ mesially and $0.78 \mathrm{~mm}$ distally 1 year after implant placement. ${ }^{18}$ This is in agreement with other studies on the current concept. 19,20

Studies have shown that the success of osseointegration, of the dental implant, will reflect clinically on the soft tissue stability (mobility) of the implant and bone levels on radiographs reference. Long term follow-up is required to closely monitor all these parameters. Various clinical methods are used to monitor hard and soft tissue changes around the dental implant. In this study, clinical peri-implant examination, radiograph and a resonance frequency analysis have been used. No local studies have been done which involves analysis of relationships between all three parameters. Therefore, the aims of this study were:

- To assess implant stability by resonance frequency analysis (RFA)

- To assess alveolar bone changes by using radiograph (periapical radiograph)

- To assess soft tissue changes by clinical assessment (probing depth)

- To assess the correlation between resonance frequency analysis (RFA) findings and radiographic findings.

- To assess the correlation between resonance frequency analysis (RFA) findings and soft tissue findings.

\section{MATERIALS AND METHODS}

\section{Study Design}

This study is a prospective observational study. The samples were implants placed in patients' jaw bone in HUSM. The implants were randomly selected and included in the study. Peri-implant tissue condition is assessed clinically and radiologically at pre-loading and post-loading stages.

The sampling frame was based on the following inclusion and exclusion criteria. Patients with dental implants placed at HUSM were included in the study. However, any systemic medical condition that could interfere with the surgical procedure or planned treatment (e.g., uncontrolled diabetes), current pregnancy at the time of recruitment, physical handicaps that would interfere with the ability to perform adequate oral hygiene, patients who smoke more than 10 cigarettes per day, medication which interferes with bone formation, history of local radiation therapy, severe bruxism or clenching habits, patient with bone pathology (e.g., sarcoma, Paget's disease, fibrous dysplasia, osteomyelitis were excluded from the study.

The dependent variables consisted of clinical and radiological measurements which were; implant stability by resonance frequency analysis (RFA) measured as ISQ, alveolar bone changes from two sites, mesial and distal, by digital radiograph (periapical radiograph). Measurements were made using Romexis software and peri-implant soft tissue changes by clinical assessment; probing depth from four sites (mesial, midfacial, distal, midpalatal) using periodontal probe and measured in millimetres whereas the independent variables consisted of data extracted from clinical record note of patients which were; age, sex, race, history of medical problems and social history such as smoking. 


\section{Sample Size Calculation}

Power and sample size calculated using PS software. The sample size with a power of $80 \%$, the alpha was 0.05 . Sample size calculation showed in Table 1.

A mean number of sample was calculated to be: $\mathrm{n}=21$.

Twenty-one implants from twenty-one patients were included in the study.

\section{Research Tools}

- Resonance frequency analysis equipment (Ostell Mentor ${ }^{\circledR}$ and smart pegs)

- Digital periapical radiograph and measurement using Planmeca Romexis ${ }^{\circledR}$ software on one HUSM computer HPCompaq LE1711 (serial number: 2AK00011707PPSG)

- Periodontal Probe: Manual periodontal probe was used to measure pocket depth.

\section{Data Collection Procedure}

Patients with dental implants placed at HUSM were randomly included in the study. Twelve implants were in the maxilla and nine implants were in the mandible.

\section{Resonance Frequency Analysis}

Implant stability was assessed as Resonance frequency analysis (RFA), by using Ostell Mentor ${ }^{\circledR}$ and smart pegs in which the vibration is detected and transferred to the resonance frequencies of the implant-to-bone (ITB) system and is displayed on the screen of the Ostell mento®r in the form of Implant Stability Quotient (ISQ) values. Measurements were taken before loading with crown (pre-loading stage), 3 months post-loading and 6 months post-loading. On these occasions, the crown/ bridge was removed, and a transducer was attached in a buccolingual direction, perpendicular to the bone.

\section{Periapical Radiograph}

Each digital radiograph was retrieved, marked and measured using Planmeca Romexis ${ }^{\circledR}$ software. A periapical radiograph was taken for radiological examination of implants at pre-loading and 6 months post-loading stage. The long cone paralleling technique was used when digital periapical radiograph was taken.

Implant bone level was evaluated using the implantabutment interface as a reference point. The distance between this point and the first visible bone-to-implant contact was measured on the mesial and distal aspect of the implant. Implant bone loss was calculated as the difference between implant bone level at baseline or preloading stage and post-loading 6 months.

\section{Probing Depth}

- Probing depth was measured by using the Manual periodontal probe. Probing depth was measured on three occasions, the pre-loading, post-loading 3 months and post-loading 6 months. The measurement was done to the nearest $0.5 \mathrm{~mm}$ at four sites per implant (mesial, midfacial, distal, palatal) with a manual periodontal probe. Probing depends on force, angulation, and size of the probe. In theory, the pressure applied during probing should be about $30 \mathrm{~g}$, but in the actual clinical scenario, adequate pressure is applied until resistance is felt and assuming the base of pocket has been reached, measurement is then taken. Plaque levels, bleeding on probing and gingival recession was not assessed in this study.

\section{Ethical Consideration}

Ethical approval was obtained from The Human Research and Ethics Committee USM (HREC) (JEPeM Code: USM/ JEPeM/1406242). It complies with the Declaration of Helsinki. Consent was obtained from all patients involved in this study. All information is kept confidential and can only be accessed by researchers. Information was obtained from each patient and the data recorded in a survey form.

\section{Statistical Analysis}

The data were verified and analyzed statistically using IBM SPSS Statistics Version 22.0 (Chicago, IL, USA) with

Table 1: Sample size calculation

\begin{tabular}{lccc}
\hline Objective & Formula & $\begin{array}{l}\text { Standard } \\
\text { deviation }(\sigma)\end{array}$ & Precision ( $\Delta)$ \\
\hline $\begin{array}{l}\text { Objective 1 } \\
\text { Implant stability quotient by RFA (ISQ) (Hsu et al. 2013) }\end{array}$ & $\mathrm{n}=\frac{1.96 \sigma^{2}}{\Delta}$ & 1.9 & 0.8 \\
\hline $\begin{array}{l}\text { Objective 2 } \\
\text { Radiographic implant bone loss (Dierens et al. 2013) }\end{array}$ & $\mathrm{n}=\frac{1.96 \sigma^{2}}{\Delta}$ & 1.7 & 0.7 \\
\hline $\begin{array}{l}\text { Objective 3 } \\
\text { Implant probing depth (Dierens et al. 2013) }\end{array}$ & $\mathrm{n}=\frac{1.96 \sigma^{2}}{\Delta}$ & 2.5 \\
\hline
\end{tabular}


confidence set at $5 \%(p<0.05)$ to test for significance. Mean values and standard deviations were calculated for all continuous variables (resonance frequency analysis, bone level on periapical radiograph and periodontal index).

Multiple comparisons for RFA and probing depth was done with ANOVA and post-hoc test.

Student T-test was done for bone loss. The existence of significant differences between findings was analyzed by student T-test for one factor and ANOVA and post-hoc test for multiple comparisons.

To find possible correlations between ISQ and other parameters such as marginal bone loss and probing depth, the Spearman correlation test was used. A statistically significant change, difference, or correlation was considered at a $p<0.05$.

\section{Reliability}

Assessment of the measurements reliability was done by randomly selected measurements; 10 samples were evaluated by another researcher after each assessment period to determine the reliability of the findings. To determine intra- and inter-examiner agreements, the Kappa statistics were used. Between the investigators, there was 100\% intra- and inter-examiner agreement. For errors associated with measurements, all procedures such as measurements involving resonance frequency analysis (RFA), bone loss (radiograph) and periodontal depth were repeated two times by the same investigator. To assess the reliability of the measurements, intraclass correlation coefficients were performed and the coefficients of the reliability of the measurements were between 0.93 and 0.97 .

\section{RESULTS}

From the 21 implants in 21 patients, 12 implants were in the maxilla and 9 implants were in the mandible. The 19 implants were treated for single tooth replacements, whereas the remaining 3 were treated as 3 unit bridges.

\section{RFA Findings}

Table 2 shows the RFA measured as ISQ at different time intervals. As measured with RFA, the implant stability increased with time, with no differences between single and multiple implants. For all implants, measurements showed a mean ISQ value of 61.7 (SD 1.178) at baseline, 63.3 (SD 0.995) at 3 months post-loading and 66.2 (SD 2.561) at 6 months post-loading. The average change from pre-loading to 6 months post-loading was highly significant $(p<0.005)$.

\section{Probing Depth Findings}

In Table 3, changes in probing depths at different time intervals are shown. A trend towards a reduction in probing depth from probing the depth of $1.767 \mathrm{~mm}$ at preloading to $1.671 \mathrm{~mm}$ at post-loading 3 months and to 1.600 $\mathrm{mm}$ at post-loading 6 months was shown. There were no statistically significant changes over time $(p>0.005)$

\section{Radiographic Finding}

Table 4 depicts the changes in the mesial and distal bone levels at pre-loading and at 6 months post-loading. At 6 months of function, radiographic examination yielded $0.786 \mathrm{~mm}$ mesial bone loss and $0.8 \mathrm{~mm}$ distal bone loss. It was found to be highly statistically significant $(p<0.005)$, but within the acceptable range. ${ }^{18-20}$

\section{CORRELATIONS}

Table 5 shows Spearman's rank-order correlation was used to determine the relationship between implant stability (RFA/ISQ) with radiographic findings, and implant stability (RFA/ISQ) with probing depth. Table 4 depicts that there was no significant $\mathrm{p}>0.05$ (mesial: $\mathrm{rs}$ is $0.047, p=0.836$; distal: rs is $0.025, p=0.914$ ) correlation between implant stability and bone loss (mesial and distal), Correlation between implant stability and probing depth was also not statistically significant, $p>0.05$ (rs is $-0.253, p=0.269$ ).

Table 2: Resonance frequency analysis (Implant Stability Quotient, ISQ) at different time interval

\begin{tabular}{|c|c|c|c|c|c|c|}
\hline \multirow[b]{2}{*}{ Variable } & \multirow[b]{2}{*}{ Mean } & \multirow[b]{2}{*}{$S D$} & \multirow[b]{2}{*}{ Multiple comparison } & \multicolumn{2}{|c|}{$95 \% \mathrm{Cl}$} & \multirow[b]{2}{*}{$p$ value } \\
\hline & & & & Lower & Upper & \\
\hline Preloading & 61.691 & 1.178 & Preloading vs post-loading (3 month) & -2.883 & -0.260 & $0.014^{*}$ \\
\hline Post-loading (3 months) & 63.262 & 0.995 & Preloading vs post-loading (6 month) & -5.860 & -3.236 & $0.000^{* *}$ \\
\hline Post-loading (6 months) & 66.238 & 2.561 & Post-loading (3 month) vs Post-loading (6 month) & -4.288 & -1.664 & $0.000 * *$ \\
\hline
\end{tabular}

Table 3: Probing depth at different time intervals

\begin{tabular}{|c|c|c|c|c|c|c|}
\hline \multirow[b]{2}{*}{ Variable } & \multirow[b]{2}{*}{ Mean } & \multirow[b]{2}{*}{$S D$} & \multirow[b]{2}{*}{ Multiple Comparison } & \multicolumn{2}{|c|}{$95 \% \mathrm{Cl}$} & \multirow[b]{2}{*}{$p$ value } \\
\hline & & & & Lower & Upper & \\
\hline Pre-loading & 1.767 & 0.489 & Preloading vs 3 month & -0.273 & 0.463 & 1.000 \\
\hline Post-loading (3 months) & 1.671 & 0.451 & Preloading vs 6 month & -0.201 & 0.535 & 0.808 \\
\hline Post-loading (6 months) & 1.600 & 0.511 & 3 month vs 6 month & -0.297 & 0.440 & 1.000 \\
\hline
\end{tabular}


Table 4: Marginal bone levels and bone loss at different time intervals

\begin{tabular}{lllll}
\hline \multicolumn{5}{c}{ Post- } \\
& Pre- & loading & & \\
& loading & 6 months & & \\
& Mean & Mean & Mean & \\
& $(S D)$ & $S D$ & Bone loss & \\
Variable & $n=21$ & $n=21$ & $(95 \%$ Cl) & p value \\
\hline Mesial & 0.476 & 1.219 & -0.743 & $0.000^{*}$ \\
& $(0.625)$ & $(0.202)$ & $(-1.180,0.391)$ & \\
Distal & 0.495 & 1.314 & -0.752 & $0.002^{* *}$ \\
& $(0.087)$ & $(0.287)$ & $(-1.298,0.302)$ & \\
\hline
\end{tabular}

* Highly significant

** Moderately significant

\section{DISCUSSION}

In the present study, we assessed peri-implant tissue changes within the 1-year duration based on radiological and clinical examinations. No differences in periimplant changes during this 1 year were observed in all parameters, regardless of site of implant and type of prostheses, none of the implants failed during the study period.

Conventional radiography is a widely-used technique in clinical practice to monitor long term changes in the peri-implant bone. However, it should be noted that minor changes in bone morphology of the crestal area, may not be revealed until a significant size and shape is reached. ${ }^{21,22}$ In this respect, a high proportion of false negative findings is yielded by conventional radiography and hence, has a rather low sensitivity for detecting early pathological and/or remodeling changes. ${ }^{22,23}$ For long-term monitoring of implants, DIB (the Distance from the Implant shoulder to the alveolar bone crest) has been proposed to represents a reliable radiographic parameter, ${ }^{21,22,24,25}$ provided that optimal exposure geometry has been achieved. It is important that the landmark to be used as a reference in two-stage submerged implant systems is clearly defined. ${ }^{22}$ In the present study, long cone parallelling technique was used while taking the digital periapical radiograph. A radiograph is taken to evaluate implant bone level using the implant-abutment interface as a reference point. The distance between this point and the first visible bone-to-implant contact was measured at both sides of the implant. Implant bone loss was calculated as the difference between implant bone level at baseline or pre-loading stage and post-loading 6 months. A low proportion of false positive findings is found with conventional radiographs, hence, yields high specificity for the detection of peri-implant bone loss, ${ }^{22}$ but this characteristic limits radiographs to be confirmatory rather than exploratory. ${ }^{22}$ Radiographic examination 1 year after implant placement, revealed mean bone loss of $0.78 \mathrm{~mm}$ mesially and $0.77 \mathrm{~mm}$ distally, which is in
Table 5: Correlations between RFA and radiographic findings, RFA and probing depth

\begin{tabular}{ll}
\hline ISQ and bone loss (mesial) & $\begin{array}{l}\text { Correlation coefficient } \\
\text { (2-tailed) } 0.839\end{array}$ \\
\hline ISQ and bone loss (distal) & 0.914 \\
ISQ and probing depth & 0.269 \\
\hline
\end{tabular}

Correlation is significant at the 0.05 level (2-tailed)

agreement with other studies on the current concept that $<1 \mathrm{~mm}$ marginal bone loss occurs in the first year. ${ }^{18-20}$ There was no marked difference in marginal bone loss between implants placed in maxilla and mandible in this study, this may be due to sufficient bone preoperatively and the ability to achieve satisfactory primary stability. There was also no marked difference in marginal bone loss between different types of prostheses, a single tooth and 3 unit bridges in this present study.

Several clinical and mechanical parameters contribute to the primary stability of an implant. ${ }^{26}$ Bone density (location of the bone), implant design, and surgical technique determine primary implant stability. ${ }^{27}$ According to Leckholm and Zarb index, ${ }^{28}$ bone density is commonly assessed in a subjective manner by the surgeon during implant placement, several objective measurement techniques are available today such as resonance frequency measurement (RFA), Periotest, and insertion torque measurements. ${ }^{29}$ The implant stability increased with time as measured with RFA. An increasing pattern of ISQ values of an implant, indicates higher implant stability and successful osseointegration, hence a good prognosis, whereas a decreasing pattern of ISQ values may indicate to the clinician that the implant may be failing. This is useful for long term clinical monitoring of implants.

A mean probing depth of $1.6 \mathrm{~mm}$ after 1 year of implant placement (6 months of function) was found in this study, which can be considered a normal phenomenon around implants. An interesting observation was the decreasing trend in probing depth between 6 months post-implant loading $(1.767 \mathrm{~mm}$ ) and upon study termination $(1.6 \mathrm{~mm})$. Similar shrinkage in pocket depth was reported to decrease from $3.6 \mathrm{~mm}$ at 3 months to $3.2 \mathrm{~mm}$ at 12 months of follow-up ${ }^{30}$ and was also reported in earlier literature. ${ }^{31}$

We observed a non-significant increase in marginal bone loss with time. But no correlations between marginal bone levels and ISQ values could be found. This is in keeping with a previous study by Fischer et al. ${ }^{29}$ There was also no correlation between ISQ values and probing depth found in this study.

\section{CONCLUSION}

In conclusion, the experimental results indicate that radiologically, peri-implant bone loss occurs, within an acceptable range as reported by many other studies. The ISQ increases with time which corresponds to a higher 
resonance frequency thus indicates a more stable ITB system and successful osseointegration. The pattern of probing depth was found to decrease with time which has also been reported in other studies. It was also found that there was no statistically significant correlation found between implant stability with bone loss and probing depth. It can be emphasized that peri-implant tissue assessment is crucial in predicting the prognosis and success of an implant. RFA provides a convenient non-invasive way for the clinicians to assess and estimate tissue status and predict whether an implant is successful or failing, however, periodic radiographic and periimplant probing depth is essential.

\section{REFERENCES}

1. Branemark PI. Osseointegration and its experimental background. J Prosthet Dent 1983;50:399-410.

2. Branemark R, Branemark P, Rydevik B, Myers RR. Osseointegration in skeletal reconstruction and rehabilitation: a review. J Rehab Res Dev 2001;38:175-182.

3. Li W, Lin D, Rungsiyakull C, Zhou S, Swain M, Li Q. Finite element based bone remodeling and resonance frequency analysis for osseointegration assessment of dental implants. FinElem Analys Des 2011;47:898-905.

4. Yang SM, Shin SY, Kye SB. Relationship between implant stability measured by resonance frequency analysis (RFA) and bone loss during early healing period. Oral Surg Oral Med Oral Path Oral Radiolog Endodont 2008;105: e12-e19.

5. Huang HL, Tu MG, Fuh LJ, Chen YC, Wu CL, Chen SI et al. Effects of elasticity and structure of trabecular bone on the primary stability of dental implants. J Med Biol Eng 2010; 30:85-89.

6. Oh JS, Kim SG, Lim SC, Ong JL. A comparative study of two noninvasive techniques to evaluate implant stability: Periotest and Osstell Mentor. Oral Surg Oral Med Oral Path Oral Radiolog Endodont 2009;107:513-518.

7. Puleo D, Nanci A. Understanding and controlling the boneimplant interface. Biomat 1999;20:2311-2321.

8. Zhou Y, Jiang T, Qian M, Zhang X, Wang J, Shi B, et al. Roles of bone scintigraphy and resonance frequency analysis in evaluating osseointegration of endosseous implant. Biomat 2008; 29:461-474.

9. Lin D, Li Q, Li W, Swain M. Bone remodeling induced by dental implants of functionally graded materials. Journal of Biomedical Materials Research Part B: App Biomat 2010; 92:430-438.

10. Meredith N. Assessment of implant stability as a prognostic determinant. Int JProsth 1997;11:491-501.

11. Cairo F, Pagliaro U, Nieri M. Soft tissue management at implant sites. J ClinPeriodont 2008;35:163-167.

12. Small PN, Tarnow DP. Gingival recession around implants: a 1-year longitudinal prospective study. Int J Oral Maxillofac Implants 2000;15:527-532.

13. Berglundh T, Lindhe J, Ericsson I, Marinello C, Liljenberg B, Thornsen $\mathrm{P}$. The soft tissue barrier at implants and teeth. Clin Oral Implants Res 1991;2:81-90.
14. Abrahamsson I, Berglundh T, Glantz PO, Lindhe J. The mucosal attachment at different abutments. J Clin Periodont 1998;25:721-727.

15. Grunder U, Gracis S, Capelli M. Influence of the 3-D bone-toimplant relationship on esthetics. Int J Periodontics Restorative Dent 2005;25:113-119.

16. Cochran DL, Hermann JS, Schenk RK, Higginbottom FL, Buser D. Biologic width around titanium implants. A histometric analysis of the implanto-gingival junction around unloaded and loaded nonsubmerged implants in the canine mandible. J Periodontol 1997;68:186-197.

17. Kan JY, Rungcharassaeng K, Umezu K, Kois JC. Dimensions of peri-implant mucosa: an evaluation of maxillary anterior single implants in humans. J Periodontol 2003;74:557-562.

18. De Rouck T, Collys K, Cosyn J. Immediate single-tooth implants in the anterior maxilla: a 1-year case cohort study on hard and soft tissue response. J Clin Periodontol 2008;35:649-657.

19. Lorenzoni M, Pertl C, Zhang K, Wimmer G, Wegscheider WA. Immediate loading of single-tooth implants in the anterior maxilla. Preliminary results after one year. Clin Oral Implants Res 2003;14:180-187.

20. Tsirlis AT. Clinical evaluation of immediate loaded upper anterior single implants. Implant Dent 2005;14:94-103.

21. Lang NP, Hill RW. Radiographs in periodonties. J Clin Periodontol 1977;4:16-28.

22. Lang NP, Wilson TG, Corbet EF. Biological complications with dental implants: their prevention, diagnosis and treatment Note. Clin Oral Implants Res 2000;11:146-155.

23. Brägger U, Pasquali L, Rylander H, Carnes D, Kornman KS. Computer-assisted densitometric image analysis in periodontal radiography. J Clin Periodontol 1988;15:27-37.

24. Buser D, Weber HP, Lang N. Tissue integration of nonsubmerged implants. 1-year results of a prospective study with 100 ITI hollow-cylinder and hollow-screw implants. Clin Oral Implants Res 1990;1:33-40.

25. Weber H, Buser D, Fiorellini J, Williams R. Radiographic evaluation of crestal bone levels adjacent to nonsubmerged titanium implants. Clin Oral Implants Res 1992;3:181-188.

26. Hsu J-T, Huang H-L, Tsai M-T, Wu A-J, Tu M-G, Fuh L-J. Effects of the 3D bone-to-implant contact and bone stiffness on the initial stability of a dental implant: micro-CT and resonance frequency analyses. IntJ Oral Maxillofac Surg 2013;42:276-280.

27. Sennerby L, Meredith N. Implant stability measurements using resonance frequency analysis: biological and biomechanical aspects and clinical implications. Periodontol 2000 2008;47:51-66.

28. Lekholm U, Gunne J, Henry P, Higuchi K, Lindén U, Bergström C, et al. Survival of the Branemark implant in partially edentulous jaws: a 10-year prospective multicenter study. Int J Oral Maxillofac Implants 1998;14:639-645.

29. Fischer K, Bäckström M, Sennerby L. Immediate and Early Loading of Oxidized Tapered Implants in the Partially Edentulous Maxilla: A 1-Year Prospective Clinical, Radiographic, and Resonance Frequency Analysis Study. Clin Implant Dent Relat Res. 2009;11:69-80.

30. Proussaefs P, Kan J, Lozada J, Kleinman A, Farnos A. Effects of immediate loading with threaded hydroxyapatite-coated rootform implants on single premolar replacements: a preliminary report. Int J Oral Maxillofac Implants 2001;17:567-572.

31. Apse P, Zarb G, Schmitt A, Lewis D. The longitudinal effectiveness of osseointegrated dental implants. The Toronto Study: peri-implant mucosal response. Int J Periodontics Restorative Dent 1991;11:94-111. 